\title{
Crystallography of Widmanstätten austenite in duplex stainless steel weld metal
}

\author{
J. W. Abtibol Menezes ${ }^{1}$, H. Abreu ${ }^{1,2}$, S. Kundu 3 , H. K. D. H. Bhadeshia*2 and \\ P. M. Kelly ${ }^{4}$
}

Two kinds of austenite grow from $\delta$-ferrite during the cooling of the duplex stainless steel weld deposits studied here, Widmanstätten plates and allotriomorphs which precipitate at $\delta$ - $\delta$ grain boundaries. It is found using microtexture measurements that the preferred crystallographic orientation of the Widmanstätten austenite can be estimated using established theory if it is assumed that there is an interaction between external stress and the growing plates. It is also demonstrated that the Widmanstätten and allotriomorphic forms of austenite may not be identically oriented even when the former appears to originate from the latter; this may be a consequence of differences in the transformation mechanisms of these two forms of austenite.

Keywords: Duplex stainless steels, Welding, Crystallography, Texture

\section{Introduction}

The combination of good mechanical properties and corrosion resistance of duplex stainless steel is attributed to a microstructure of approximately equal proportions of ferrite and austenite. ${ }^{1,2}$ The alloys and associated welds are associated with fascinating metallurgy. ${ }^{3-6}$ Welding disrupts the microstructure through the localised input of heat; duplex steels can become fully ferritic on reaching temperatures in excess of $1250^{\circ} \mathrm{C}$; austenite may reform on subsequent cooling but the quantity will depend on the cooling rate. High heat input welds are associated with slower cooling and hence a greater quantity of austenite in the final microstructure. The morphology of the austenite can also vary with the welding conditions; high cooling rates seem to favour the precipitation of Widmanstätten austenite. ${ }^{7}$

Southwick and Honeycomb ${ }^{8,9}$ concluded that the decomposition of $\delta$-ferrite to austenite occurs by two different mechanisms depending upon the transformation temperature. At high temperatures the reaction occurs by a diffusional nucleation and growth process whereas at low temperatures the austenite forms by a displacive mechanism on a habit plane close to $\left\{\begin{array}{llll}1 & 3 & 3\end{array}\right\}_{\delta}$. However, the mechanism of transformation is not established because the complete set of data needed to show consistency with the phenomenological theory of martensite crystallography has never been assembled. ${ }^{10-12}$ There is some evidence for the partitioning of solutes during the formation of intragranular

\footnotetext{
${ }^{1}$ Universidade Federal do Ceará, Engenharia Metalúrgica e de Materiais Fortaleza, Brazil

2University of Cambridge, Materials Science and Metallurgy, Cambridge, UK

${ }^{3}$ TATA Steel, Research and Development Division, Jamshedpur, India ${ }^{4}$ University of Queensland, Mining, Minerals and Materials, Australia

*Corresponding author, email hkdb@cam.ac.uk
}

plates of austenite ${ }^{13}$ but the possibility that composition changes occur after transformation cannot be ruled out. Attempts at measuring the surface relief associated with the formation of the Widmanstätten austenite show some displacements but the data are qualitative and inconclusive. ${ }^{14}$

Our aim was to see whether it is possible to detect an interaction of plates of Widmanstätten austenite with the stresses that are inevitable when a bead on plate weld cools. The work is conducted using electron backscatter diffraction (EBSD), together with an analysis of the data based on the crystallographic theory of martensitic transformations, although it should be stated at the outset that this in itself may not be sufficient to establish the detailed atomic mechanism.

\section{Experimental}

The welds were deposited using AWS 2209-17 electrodes on a $12.7 \mathrm{~mm}$ thick plate of DSS UNS S31803 by the shielded metal arc welding process. The chemical compositions of both the base metal and weld metal are presented in Table 1. Table 2 lists the three kinds of welding conditions used.

Behara's etchant, a solution of $0 \cdot 3-0 \cdot 6 \mathrm{~g}$ of potassium metabisulfite in $20 \mathrm{~mL}$ of $\mathrm{HCl}$ and $100 \mathrm{~mL}$ of water was used to etch the metallographic samples.

Electron backscattered diffraction analyses were performed using an Oxford Crystal 300 system attached to a Philips XL 30 SEM. For this work, the specimens were mechanically ground and polished, to a final finish using colloidal silica. The microscope used was CAMSCAN Maxim field emission gun SEM, using a magnification of $\times 500$ with a step size of $0.5 \mu \mathrm{m}$. Orientation data were acquired from known locations in order to relate the orientation data to strain maps. Subsequent data analysis was carried out using HKL technology 'Channel5' software. 


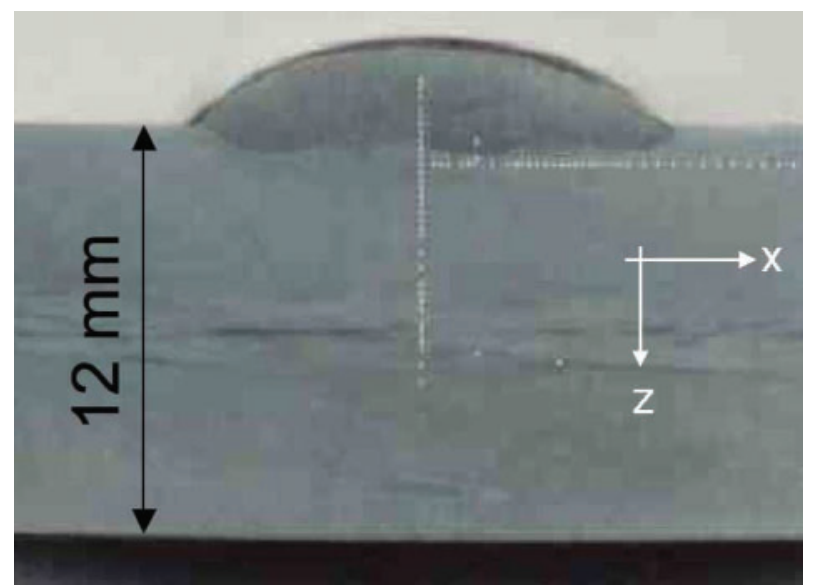

1 Shape of weld deposited with $18 \mathrm{~kJ} \mathrm{~cm}^{-1}$ of heat input, with sample reference frame marked

\section{Results}

The geometry of the bead on plate deposit is illustrated in Fig. 1 and the reference axes marked represent the sample frame of reference, which will be used later in the paper in plotting crystallographic data. The microstructure of duplex stainless steels of the type considered here is generated by transformation from the columnar grains of $\delta$-ferrite which form during solidification. Although the details are not entirely established, it is believed that the Widmanstätten austenite grows by a displacive mechanism whereas allotriomorphic austenite is considered to be a reconstructive transformation. ${ }^{8}$ Phase maps, which also illustrate the microstructure, were obtained using EBSD with a pixel size of $d=1.89 \mu \mathrm{m}$ (Fig. 2). There were few unsolved points so the dominant error in the measurement of phase fraction comes from the pixel size. A phase is presumably not detected if it covers less than half of a pixel. On these grounds, the authors estimate that the error is given by $S_{\mathrm{V}} \times 0 \cdot 5 d$, where $S_{\mathrm{V}}$ is the amount of $\gamma / \delta$ interface per unit volume. Taking the worst case scenario of the $4 \mathrm{~kJ} \mathrm{~cm}^{-1}, S_{\mathrm{V}}$ was measured to be $\sim 0 \cdot 12 \mu \mathrm{m}^{-1}$, giving a measurement error in volume fraction of the order of $\pm 0 \cdot 1$. The values of volume fraction are indicated in Fig. 2. It is reasonable that the volume fraction of austenite increases with the heat input, since a larger heat input leads to a slower cooling rate. $^{15,16}$

\section{Crystallography}

Figure 3 shows an EBSD image of the austenite together with separate images of $\delta$-ferrite, allotriomorphic austenite $\gamma$ and Widmanstätten austenite $\gamma_{\mathrm{w}}$; similar images are available for the other two heat input samples but are excluded for brevity. The number of variants per $\delta$-ferrite grain is much smaller than the 24 possible theoretically. The fact that the $\gamma$ and $\gamma_{w}$ can be separated on the basis of their Euler angles may be, as discussed later, significant from the point of view of the mechanism of transformation.

The phenomenological theory of martensite crystallography gives a complete description of the mathematical connection between the orientation relationship, the habit plane and the shape deformation for each plate that forms by displacive transformation. ${ }^{10-12,17-19}$ The most common application of this theory is to the transformation of the face centred cubic (f.c.c.) austenite into a body centred cubic (b.c.c.) or body centred tetragonal martensite. Here the authors wish to study the reverse reaction, from the b.c.c. $\delta$-ferrite to f.c.c. austenite.

Table 3 lists some crystallographic data for the b.c.c. $\rightarrow$ f.c.c. transformation. The data for brass (f.c.c. $\alpha$, b.c.c. $\beta$ ) are due to Cornelis and Wayman. ${ }^{20}$ Calculations based on phenomenological theory depend on the lattice parameter ratio of the parent and product phases. The ratio for brass is similar to that in duplex stainless steel; the X-ray measured lattice parameters of the weld metal were found to be $a_{\delta}=2.8894 \AA$ and $a_{\gamma}=3.6358 \AA$. Two further solutions are also listed in Table 3 from the work of Bowden and Kelly. ${ }^{21,22}$ The orientation relationships listed as the coordinate transformation matrices help predict the transformation texture as a function of a given parent austenite texture. $^{23-25}$ Each grain of $\delta$-ferrite can transform into 24 variants of $\gamma_{\mathrm{w}}$, but it is possible that some variants are favoured over others due to the development of residual stress as the bead on plate deposit cools. Figure 4 shows a stereogram defined relative to the crystallographic axes of $\delta$-ferrite, with $\{100\}_{\gamma}$ poles for all the orientations listed in Table 3 together with the expectation from the exact Kurdjumov-Sachs orientation. ${ }^{26}$ The results from all four orientations are similar and experiments of the type reported here probably cannot distinguish between them because as will be seen later, the detected intensity from austenite is diffuse enough to make such distinctions difficult. It is probable that the austenite contains dislocations due to the mechanism of transformation and due to plasticity induced by residual stress during the cooling of the weld. When comparing the calculations described later against experimental data on variant selection, best agreement was found using the solutions corresponding to brass and 'solution 2', the latter being slightly more consistent. Therefore, the data corresponding to 'solution 2' are henceforth used throughout the paper.

Table 2 Welding conditions

\begin{tabular}{llll}
\hline Sample & Current, A & $\begin{array}{l}\text { Welding speed, } \\
\text { cm min }\end{array}$ & $\begin{array}{l}\text { Heat input, } \\
\mathrm{kJ} \mathrm{cm}^{-1}\end{array}$ \\
\hline 1 & 120 & 10 & 18 \\
2 & 120 & 20 & 9 \\
3 & 80 & 30 & 4 \\
\hline
\end{tabular}

Table 1 Chemical compositions, wt- $\%$

\begin{tabular}{lllllllllllll}
\hline & Cr & Ni & Mo & N & C & Mn & S & P & Si & Cu & Nb & Fe \\
\hline Plate & 22.22 & 5.59 & 3.08 & 0.18 & 0.018 & 1.48 & 0.001 & 0.019 & 0.45 & 0.28 & 0.021 & Bal. \\
Electrode & 23.0 & 9.0 & 3.0 & 0.15 & 0.02 & 0.8 & - & - & 0.8 & - & Bal. \\
\hline
\end{tabular}




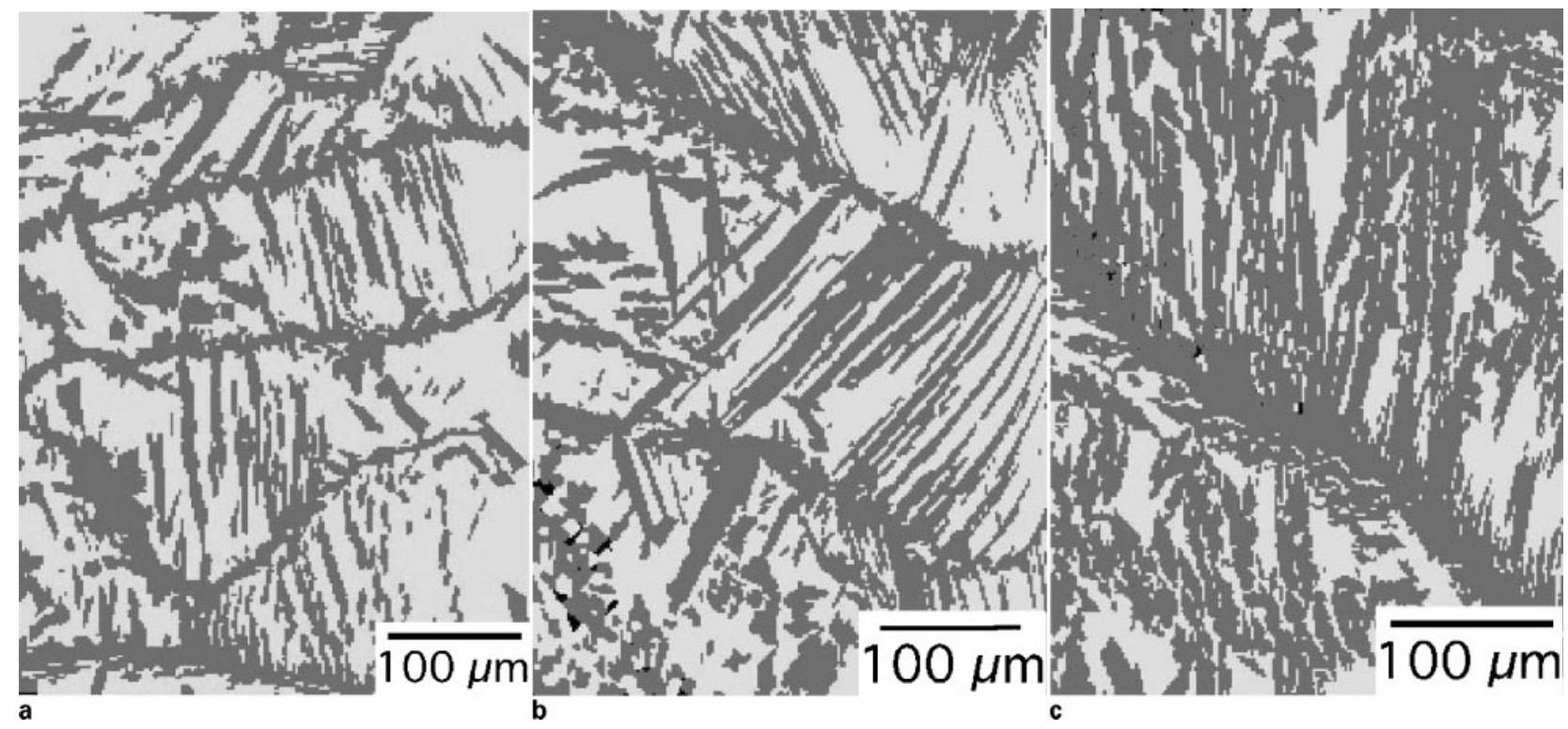

a $4 \mathrm{~kJ} \mathrm{~cm}^{-1}$ with $V_{\gamma} \approx 0.41 \pm 0.1 ;$ b $9 \mathrm{~kJ} \mathrm{~cm}^{-1}$ with $\mathrm{V}_{\gamma} \approx 0.49 \pm 0.1 ; c 18 \mathrm{~kJ} \mathrm{~cm}^{-1}$ with $V_{\gamma} \approx 0.65 \pm 0.1$

2 Phase maps showing $\delta$-ferrite as light grey and austenite as dark grey

Finite element simulations of bead on plate welds ${ }^{27}$ indicate that the longitudinal stress in the bead (which is the largest component of stress) should be compressive during cooling although the sign may reverse once ambient temperature is reached. ${ }^{28}$ In the present case the transformation from $\delta$-ferrite occurs at temperatures in access of $700^{\circ} \mathrm{C}$ in which case it is justified to assume that the bead was in compression before transformation.
The effect of this stress on variant selection can be expressed using the Patel and Cohen method, ${ }^{29}$ in which the interaction of a plate with the stress provides the mechanical driving force $U$ for transformation

$$
U=\sigma_{\mathrm{N}} \zeta+\tau S
$$

where $\sigma_{\mathrm{N}}$ is the stress component normal to the habit

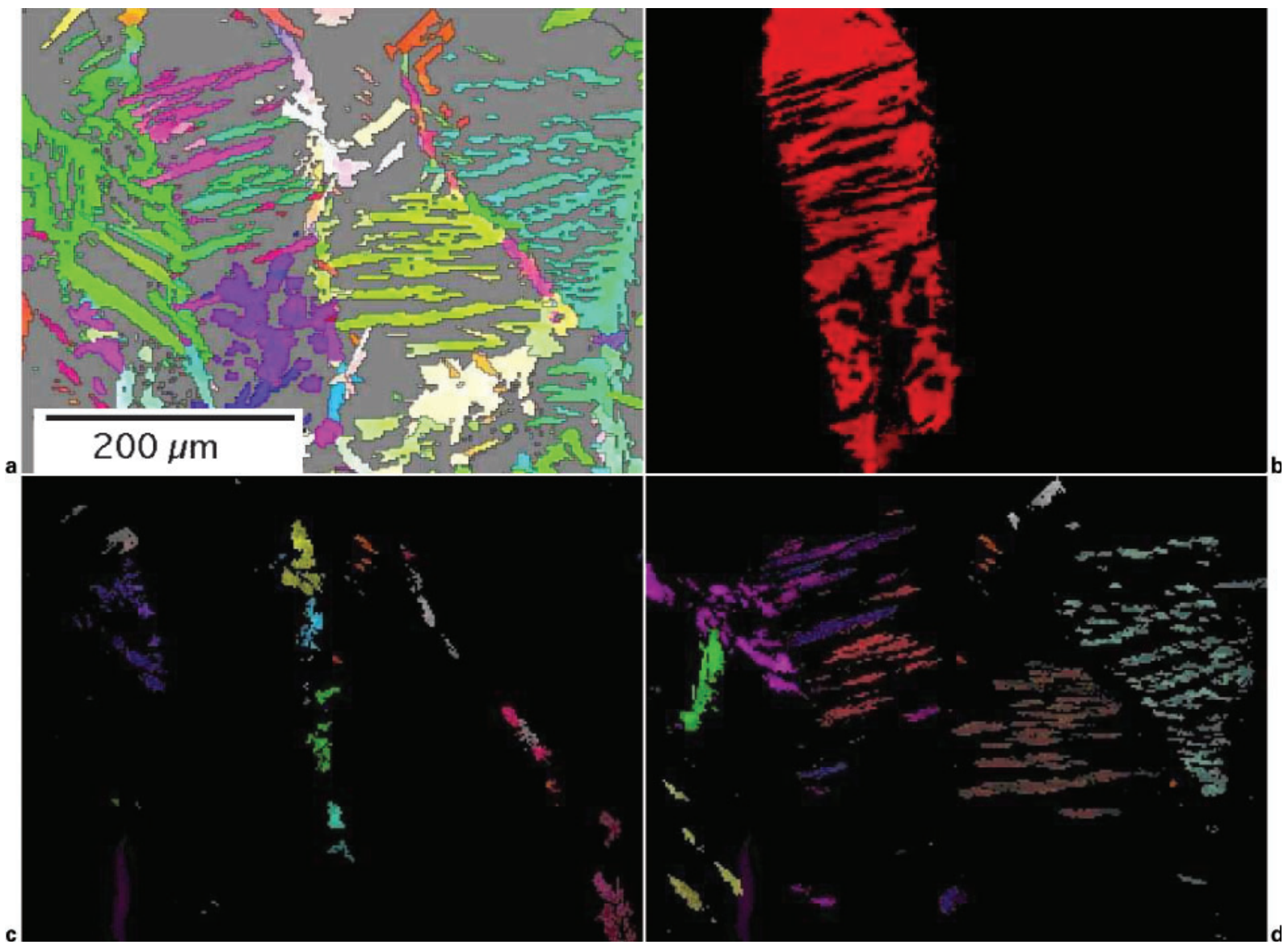

a EBSD image showing only austenite; $b$ only $\delta$-ferrite; $c$ allotriomorphic austenite; $d$ Widmanstätten austenite 3 Crystallographic deconvolution of $4 \mathrm{~kJ} \mathrm{~cm}^{-1}$ deposit 


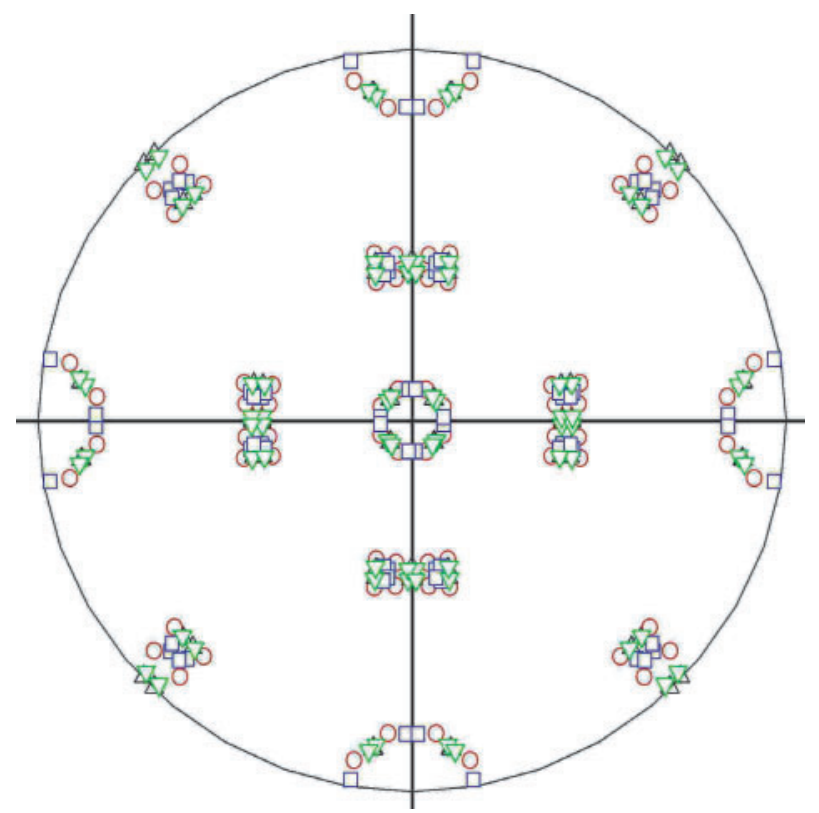

4 Plots of expected positions of $\{100\}$ poles of austenite relative to crystallographic axes of $\delta$-ferrite, assuming brass (black triangles), solution 1 (blue squares), solution 2 (green, inverted triangles) and exact Kurdjumov-Sachs (red circles) orientation relationship; poles from both halves of stereographic sphere are plotted

plane, $\tau$ is the shear stress resolved on the habit plane in the direction of shear and $\zeta$ and $s$ are the respective normal and shear strains associated with transformation. The normal and shear stresses on the habit plane can be calculated by resolving the external stress parallel to $\mathrm{p}$ and on to the habit plane in the direction of shear, using the data listed in Table 3, for each possible orientation of an austenite plate. All plates whose shape deformations comply with the compressive residual stress along the direction $y$ in Fig. 1 are favoured and included here in the calculation of transformation texture.

Calculations were conducted on all three welds assuming the crystallography consistent with 'solution 2', which were then compared against experimental data, assuming that only those variants which comply with the stress $(U>0)$ form, and then repeating the analysis for the those variants which are not favoured $(U<0)$. The experimental data in these comparisons are confined to the Widmanstätten plates of austenite.

The results are illustrated in Fig. 5 for all three welds; note that using imaging such as that illustrated in Fig. 3, the authors have only used information from the Widmanstätten austenite (rather than the allotriomorphs) in plotting the pole figures. It is evident that most of the observed intensity can be explained if it is assumed that only the 12 favoured variants grow; the minority intensity not explained in this way is consistent with the formation of some unfavoured variants. The latter observation that some plates form which do not comply with the stress is not surprising since in addition to the mechanical driving force, there is a chemical driving force for transformation of $\delta$-ferrite which encourages the formation of all 24 variants. It is known that the ratio of the mechanical driving force to total driving force must be large for favoured variants to dominate. ${ }^{24}$ The chemical free energy change accompanying the transformation of $\delta$-ferrite into an equilibrium mixture of $\delta+\gamma$ is illustrated in Fig. 6; this is likely to be an overestimate of the driving force because

Table 3 Crystallographic details

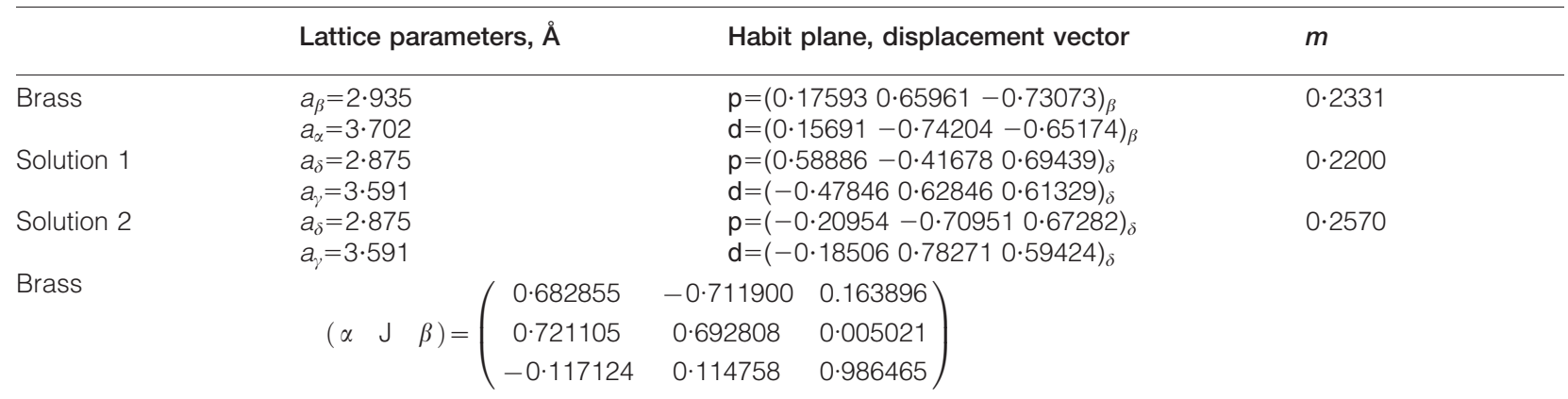

Solution 1

$$
\left(\begin{array}{lll}
\delta & \mathbf{J} & \gamma
\end{array}\right)=\left(\begin{array}{ccc}
0.677740 & 0.723985 & 0.128506 \\
-0.167069 & -0.018574 & 0.985770 \\
0.716070 & -0.689565 & 0.108367
\end{array}\right)
$$

Solution 2

$$
\left(\begin{array}{lll}
\delta & \mathbf{J} & \gamma
\end{array}\right)=\left(\begin{array}{ccc}
0.723985 & 0.689565 & 0.018574 \\
-0.128506 & 0.108367 & 0.985770 \\
0.677740 & -0.716070 & 0.167069
\end{array}\right)
$$

$a$ is the lattice parameter of the phase identified by the subscript. $p, d$ and $m$ are the unit normal to the habit plane, the unit displacement vector and the magnitude of the displacement vector, respectively. $(\alpha \mathrm{J} \beta)$ is the coordinate transformation matrix relating the bases defined by the basis symbols $\alpha$ and $\beta$. 


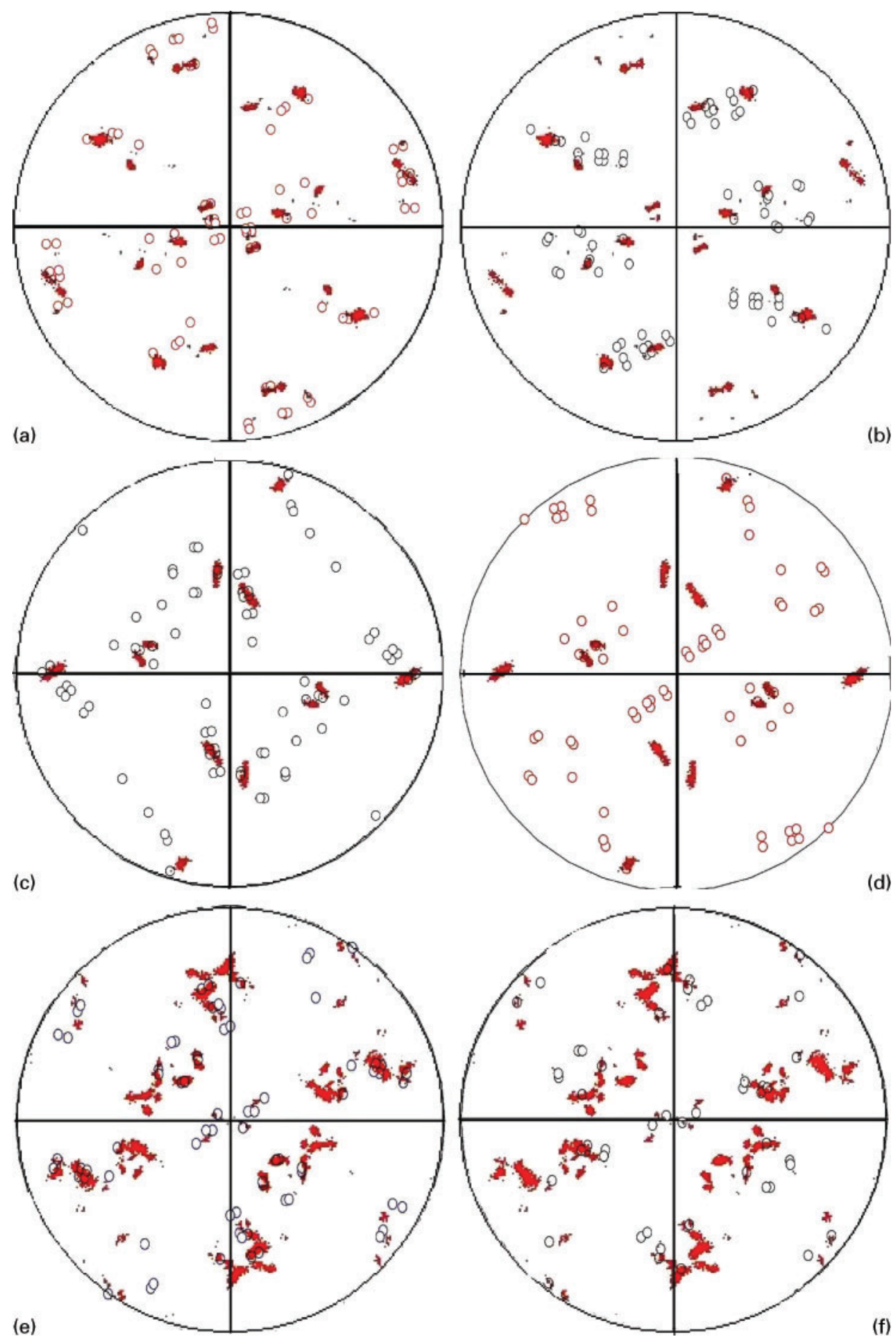

a $U>0,4 \mathrm{~kJ} \mathrm{~cm}^{-1} 1 ; b U<0,4 \mathrm{~kJ} \mathrm{~cm}^{-1} ; c U>0,9 \mathrm{~kJ} \mathrm{~cm}^{-1} ; d U<0,9 \mathrm{~kJ} \mathrm{~cm}^{-1} ; e U>0,18 \mathrm{~kJ} \mathrm{~cm}^{-1} ; f U<0,18 \mathrm{~kJ} \mathrm{~cm}^{-1}$

5 Stereograms plotted on sample reference frame with $z$ vertical and $y$ horizontal: circles are calculated poles and red intensity are corresponding measurements; with respect to calculations, a,c,e represent favoured variants, $b, d, f$ represent variants which do not comply with compression along $y$

the authors do not allow for the strain energy due to the accommodation of the shape deformation accompanying transformation, typically the order of $400 \mathrm{~J} \mathrm{~mol}^{-1}$ The calculations were conducted using MTDATA with the SGTE database ${ }^{30}$ and such calculations are known to be reliable for duplex stainless steels. ${ }^{31}$ From these data, the chemical free energy is likely to be ten times greater than the mechanical driving force over the approximate transformation temperature range (700 $800^{\circ} \mathrm{C}$ ), although the terms would be much more equal if the strain energy is accounted for.

\section{Allotriomorphic austenite}

The authors have not attempted here to predict the orientation of allotriomorphic austenite because it is a reconstructive transformation and hence does not have a shape deformation other than an isotropic volume change, which should only react to hydrostatic stress. A variety of other criteria, such as the optimum orientation for nucleation while in contact with two or more $\delta$-ferrite grains, may determine variant selection. Indeed, the strict condition that a line must remain 


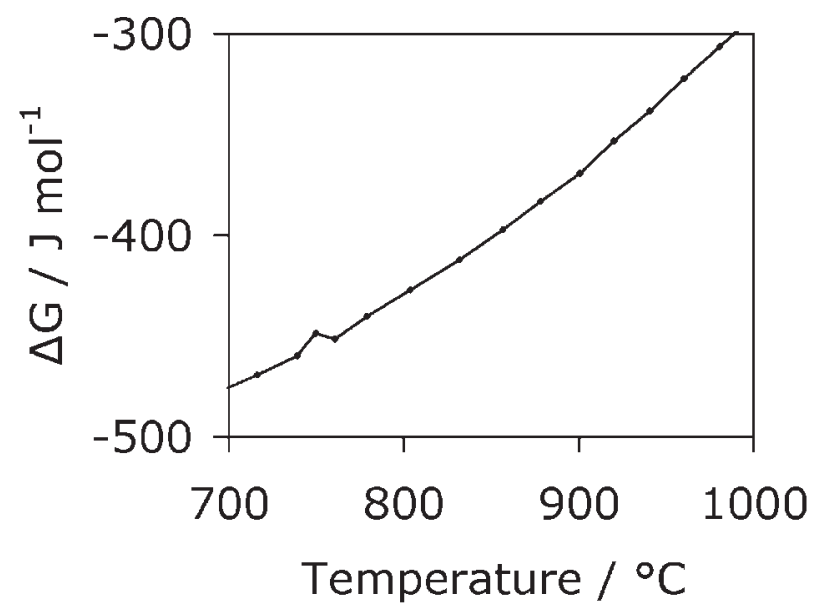

6 Calculated change in Gibbs free energy $\Delta G=G_{y+\delta}-G_{\delta}$ as function of temperature

invariant during displacive transformation. ${ }^{18,19,32-34}$ Therefore, it is not surprising that in the present work, a significant difference in orientation was found between the allotriomorphic austenite and Widmanstätten austenite, even when the latter appeared to grow from the former (Fig. 7). This result is consistent with the different mechanisms of transformation for the two kinds of austenite.

\section{Conclusion}

The crystallographic orientations of Widmanstätten austenite in bead on plate welds of duplex stainless steel can be estimated on the assumption that those variants that comply with the stress that develops during the cooling of the weld are favoured. This demonstrates that the transformation interacts in a systematic manner with the applied stress. It is found that even when Widmanstätten austenite appears to develop from allotriomorphic austenite, there is a significant relative misorientation between these two morphologies, possibly reflecting the fact that the allotriomorphs form by a diffusional transformation mechanism.

\section{Acknowledgement}

The authors are grateful to CNPq (National Council for Scientific and Technological Development) for financial support (project no. 200220/2007-1).

\section{References}

1. D. N. Noble and T. G. Gooch: 'Factors controlling the ferrite/ austenite balance in arc welded $22 \mathrm{Cr} 5 \mathrm{Ni} 2 \cdot 5 \mathrm{MoN}$ duplex stainless steel', Technical Report 321/1986, the Welding Institute, Abington, UK, 1986.

2. L. Karlsson: Anti-corros. Method. Mater., 1995, 42, 30-35.

3. W. M. Yip, H. C. Man and W. H. Ip: Sci. Technol. Weld. Join., 1999, 4, 226-232.

4. N. A. McPherson, Y. Li and T. N. Baker: Sci. Technol. Weld. Join., 2000, 5, 235-244.

5. V. Muthupandi, P. B. Srinivasan, S. K. Seshadri and S. Sundaresan: Sci. Technol. Weld. Join., 2004, 9, 47-52.

6. A. J. Ramirez, S. D. Brandi and J. C. Lippold: Sci. Technol. Weld. Join., 2004, 9, 301-313.

7. B. E. S. Lindblom, B. Lundqvist and N. E. Hannerz: Scand. J. Metall., 1991, 20, 305-315.

8. P. D. Southwick and R. W. K. Honeycombe: in 'International conference on martensitic transformations ICOMAT '79', 189-194; 1979, Boston, MIT Press.
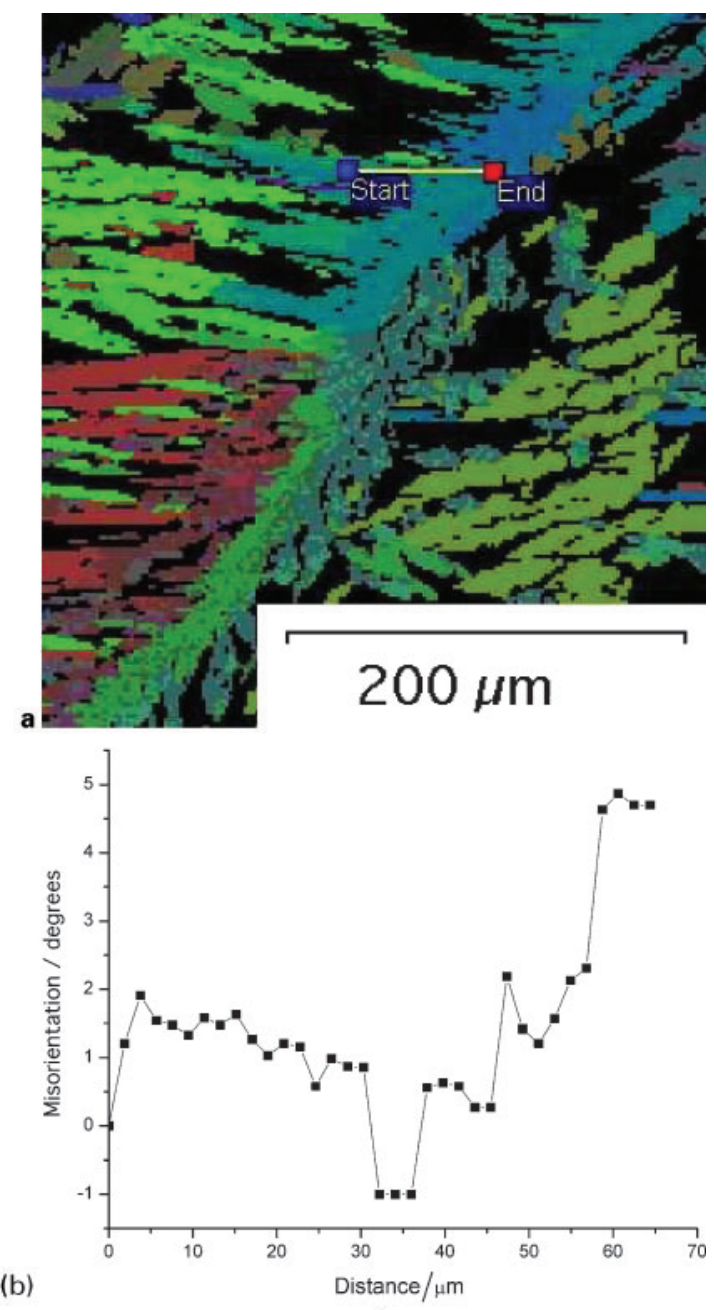

(b)

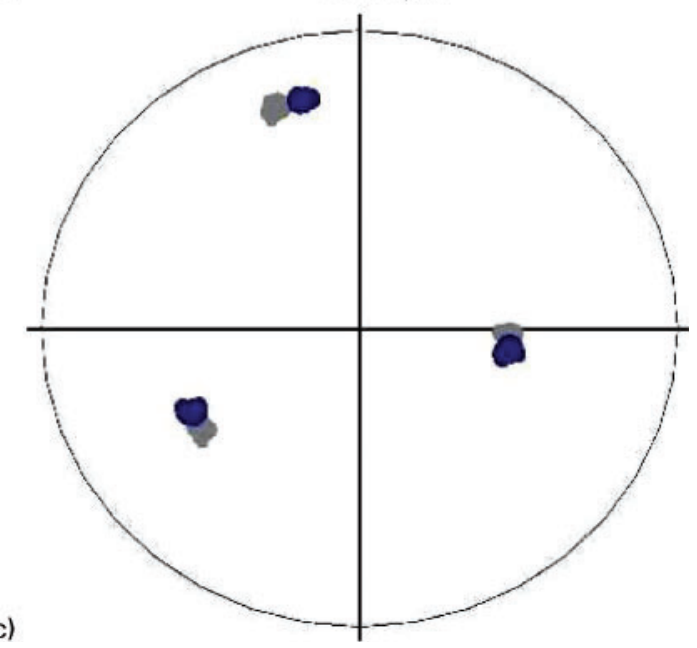

a orientation image showing location of scan; $b$ misorientation as function of distance; $c$ stereogram illustrating difference in orientation - blue poles represent $\gamma_{w}$

7 Difference in orientation between $\gamma_{w}$ and associated allotriomorphic austenite $\left(18 \mathrm{~kJ} \mathrm{~cm}^{-1}\right.$ weld)

9. P. D. Southwick and R. W. K. Honeycombe: Met. Sci., 1980, 7, 253-261.

10. J. S. Bowles and J. K. MacKenzie: Acta Metall., 1954, 2, 129-137.

11. J. K. Mackenzie and J. S. Bowles: Acta Metall., 1954, 2, 138-147.

12. M. S. Wechsler, D. S. Lieberman and T. A. Read: Trans. AIME J. Met., 1953, 197, 1503-1515.

13. S. Atamert and J. E. King: Zietschrift für Metallkunde, 1991, 82, 230-239.

14. N. I. A. Haddad: 'Development of microstructure in duplex stainless steel welds', PhD thesis, University of Cambridge, Cambridge, UK, 1989 
15. D. Rosenthal: Weld. J. Res. Suppl., 1941, 20, 220s-234s.

16. L.-E. Svensson, B. Gretoft and H. K. D. H. Bhadeshia: Scand. J. Metall., 1986, 15, 97-103.

17. J. W. Christian: 'Theory of transformations in metal and alloys, part II', 3rd edn; 2003, Oxford, Pergamon Press.

18. J. W. Christian: 'Theory of transformations in metal and alloys, part I', 3rd edn; 2003, Oxford, Pergamon Press.

19. H. K. D. H. Bhadeshia: 'Geometry of Crystals', 2nd edn; 2001, London, Institute of Materials.

20. I. Cornelis and C. M. Wayman: Acta Metall., 1974, 22, 291-300.

21. P. M. Kelly: Acta Metall., 1965, 13, 635-646.

22. H. G. Bowden and P. M. Kelly: Acta Metall., 1967, 15, 1489 1500

23. S. Kundu and H. K. D. H. Bhadeshia: Scr. Mater., 2006, 55, 779-781.

24. S. Kundu, K. Hase and H. K. D. H. Bhadeshia: Proceed. Roy. Soc. A, 2007, 463A, 2309-2328.
25. H. K. D. H. Bhadeshia, H. Abreu and S. Kundu: Int. J. Mater. Res., 2008, 99, 342-346.

26. G. V. Kurdjumov and G. Sachs: Zietschrift fr Physik A Hadrons Nuclei, 1930, 64, 325-343

27. X. Y. Shan, M. J. Tan and N. P. O'Dowd: J. Mater. Process. Technol., 2007, 192-193, 497-503.

28. N. P. O’Dowd: Private communication, 2008.

29. J. R. Patel, M. Cohen: Acta Metall., 1953, 1, 531-538.

30. NPL: MTDATA: Software, National Physical Laboratory, Teddington, UK, 2006.

31. F. H. Hayes: J. Less-Common Met., 1985, 114, 89-96.

32. J. W. Christian and A. G. Crocker: in 'Dislocations in solids', Vol. 3, 165-252; 1980, North Holland, Amsterdam, Holland, Elsevier.

33. J. W. Christian: Metall. Mater. Trans. A, 1994, 25A, 1821-1839.

34. J. W. Christian: Metall. Trans. A, 1982, 13A, 509-538. 